\title{
NARraciones de Escolares BÁsicos: DOS TAREAS DE ESCRITURA*
}

\author{
Manuel Rubio**
}

\section{Resumen}

El propósito de este artículo es describir el proceso de validación de dos tareas de escrituras y un análisis preliminar de los textos producidos por los estudiantes de $3^{\circ}, 5^{\circ}$ y $7^{\circ}$ básico. Las dos tareas se aplican a un total de 275 niños. Los resultados indican que si se define la narración en términos amplios (como secuencia de acciones en el tiempo), todos los estudiantes logran producir este tipo de textos; en cambio, si se la define en términos restringidos (como un encadenamiento de eventos que se articulan en torno a la resolución de una complicación) es la condición de escritura espontánea la que logra mayores niveles de logro, pues en la segunda condición el factor recuerdo de las imágenes y de su orden de aparición concita la mayor atención de los estudiantes. Se concluye que las dos tareas son pertinentes para que los niños de diversos niveles de educación básica produzcan textos relativamente coherentes.

Palabras clave: Producción escrita, tareas de escritura, narración, enseñanza de la lengua.

\section{Elementary School Student's Narratives: Two Writing TASKS}

\begin{abstract}
The aim of this article is to describe the validation process of two writing tasks and a preliminary analysis of texts produced by $3^{\circ}, 5^{\circ}$ and $7^{\circ}$ elementary school students. The two tasks are carried out by a total of 275 children. The results show that if narrative is defined in broad terms (as a sequence of actions in time) all students manage to produce these sort of texts. However, if defined in restrictive terms (as a sequence of events which are articulated around problem solving), spontaneous writing achieves a higher level of achievement due to the fact that the memory and order of images engage most of students' attention in the second condition. It can be concluded that both tasks are appropriate for children from a variety levels of elementary education and their production of relatively coherent texts.
\end{abstract}

Keywords: Writing skill, writing tasks, narratives, language teaching.

* $\quad$ Este trabajo forma parte del proyecto Fondecyt/iniciación 11130010, Desarrollo de la producción escrita en escolares básicos: un análisis desde la lingüística sistémico funcional.

** Chileno, Doctor en lingüística, académico del Departamento de Lingüística y Literatura de la Universidad de Santiago de Chile (USACH), Santiago, Chile, manuel.rubio@usach.cl. 


\section{Introducción}

La producción escrita es una habilidad que la mayor parte de los niños comienza a desarrollar en la enseñanza básica. A diferencia de la oralidad, la escritura exige instrucción sistemática, pues se la considera una tecnología y requiere la puesta en práctica de una serie de razonamientos anteriores al acto mismo de escribir, en el cual se ponen en juego el conocimiento temático, el establecimiento de propósitos, el conocimiento del tipo de texto que permite lograr dichos propósitos y las características de una audiencia remota (Bereiter y Scardamalia, 1982; Casssany, 1999; Flower \& Hayes 1981; Grabe \& Kaplan, 1996; Hayes, 1996; Pozo, 2001).

En efecto, contrariamente a lo que algunos piensan, la escritura es una práctica compleja de producción de significados condicionada por las demandas que emergen de situaciones comunicativas cualitativamente distintas y que impactan en los niveles de abstracción, especialización del léxico y convenciones discursivas propias de distintas esferas de la acción humana. En este sentido, escribir es un acto público, pues implica un proceso de descentramiento para ponerse en el lugar de los eventuales lectores y adoptar convenciones propias del género discursivo que se pretende producir (Beard, Myhill, Riley \& Nystrand, 2009; Kent, 1999; Flower, 1994; Hayes, 1996).

$\mathrm{Si}$ bien el curriculum escolar presenta como un eje relevante la escritura de diversos tipos de textos, los cuales debieran caracterizarse por un nivel de complejidad creciente desde el punto de vista estructural, temático, sintáctico y pragmático, pareciera que es un elemento secundario en la práctica de aula (Meneses, 2006 y 2008). En general, en diferentes contextos escolares, si bien se reconoce el valor del desarrollo de habilidades para producir textos escritos para el éxito académico, el tiempo y atención que se le dedica a actividades de escritura es bastante limitado. Una posible razón se relaciona con la preparación de los docentes para enseñar en esta área, lo cual se vería agravado por la ausencia de materiales didácticos adecuados para hacerlo (Koster, Tribushinina, de Jong \& van den Bergh, 2015).

En relación con la investigación de la escritura a nivel escolar, también se puede señalar un importante déficit. En efecto, el énfasis en el estudio de la escritura en la última década ha estado en el ámbito académico 
universitario. Cuando el objeto de estudio se centra en los escritos de escolares, se orientan al proceso de escritura y a la identificación de las prácticas de enseñanzas efectivas (Koster et al., 2015). En general, pareciera que existen pocas investigaciones cuyo objeto de estudio sea la exploración sistemática de las características lingüísticas de la producción escrita a lo largo de la educación básica (Christie \& Derewianka, 2008).

En la línea de indagar los recursos lingüísticos que evidencian los escolares básicos para producir significados, se diseñaron dos tareas de escritura centradas en la producción de narraciones. La elección de esta modalidad discursiva se debió a que existe evidencia de que es adquirida en la temprana infancia (Bosco Figuereido, 1998) y de que es un tipo de texto que regularmente se produce durante la escolaridad básica (Delicia, 2011). Según Aravena (2011), alrededor de los 9 años, los niños han alcanzado un dominio básico de esta modalidad textual. Sería el cierre en las narraciones escritas, debido a un desenlace abrupto, incompleto o mal resuelto, la parte donde se registrarían los mayores problemas (Sotomayor, Lucchini, Bedwell, Biedma, Hernández y Molina, 2013).

El propósito de este artículo es, por un lado, describir el proceso de validación de dos tareas de escrituras: una narración espontánea y otra dirigida por una secuencia de imágenes; por otro, presentar una indagación general de los textos producidos por niños de $3^{\circ}, 5^{\circ} \mathrm{y}$ $7^{\circ}$ básicos. Así, se proporciona un procedimiento metodológico para estimular la producción de textos viables de ser analizados en tanto productos que pueden ser abordados desde distintas perspectivas, dado que, como indica De Beaugrande (1997), se puede concebir un texto como la punta de un iceberg, cuya materialidad lingüística implica un conjunto de opciones en el ámbito lingüístico, retórico y contextual.

\section{Marco Teórico}

\subsection{El estudio de la producción de escrita y su enseñanza en la escuela}

La producción escrita ha sido estudiada desde tres perspectivas diferentes: una psicológica, centrada en los procesos internos que vive el escritor; una sociocultural, orientada al análisis de las prácticas discursivas que constituyen al escritor; y una lingüística, enfocada en el texto producido (Beard et al., 2009; Hyland, 2002). 
El enfoque psicológico ha estado centrado en los procesos cognitivos que experimenta un individuo que escribe, es decir, un sujeto maneja operaciones cognitivas y metacognitivas más o menos complejas (Beard et al., 2009; Nystrand, 2006).

El enfoque sociocultural enfatiza los contextos de escritura como condiciones que forma el escritor y que, al mismo tiempo, lo constituyen. El texto escrito se concibe como una co-construcción que requiere la colaboración, mediación y negociación en el ámbito de una comunidad discursiva dada (Kostouli, 2009).

Por su parte, el enfoque lingüístico describe cómo se utiliza el lenguaje en textos y contextos para crear significados. Desde esta perspectiva, se ha configurado, en el contexto anglosajón, una pedagogía de la alfabetización basada en diferentes géneros discursivos, constituida desde la lingüística sistémica funcional (Christie \& Derewianka, 2010; Rose, 2009), lo cual ha supuesto analizar los tipos de textos que se espera que los estudiantes produzcan y establecer los métodos que apoyen a los estudiantes a escribir exitosamente. Los géneros que los escolares escriben se han categorizado en siete grandes grupos: relatos (recuentos y narraciones), respuestas textuales (ejemplos, respuestas personales, revisiones, interpretación, respuestas críticas), argumentos (exposición y discusión), historias (recuento autobiográfico, recuento biográfico, recuento histórico), explicaciones (explicaciones secuenciales, explicaciones factoriales, explicaciones consecuenciales), informes (informes descriptivos, informes de clasificación, informe composicional) y procedimientos (procedimientos y recuento de procedimientos).

Según Christie y Derewianka (2010), falta una indagación sistemática de las características lingüísticas de la producción escrita de los niños y el desarrollo de la escritura está mal definido, lo cual dificulta la posibilidad de evaluarlo. Esta podría ser la razón de que en la educación escolar se le dé poca relevancia a la estimulación al desarrollo de la producción escrita (Meneses 2006 y 2008; Koster et al. 2015). En general, pareciera que los docentes no modelan la escritura y retroalimentan deficientemente a sus estudiantes. Además, se carga negativamente la actividad de escribir, puesto que básicamente se la ocupa como un mecanismo de control (Grabe \& Kaplan, 1996). 
Tres líneas de reflexión se podrían seguir para comprender la valoración negativa que se realiza de la labor escrita, a saber:

1. Los profesores manejarían una concepción pobre acerca de las funciones del lenguaje. En efecto, el niño antes de ingresar a la escuela es usuario del lenguaje en diversas formas y para el logro de diferentes propósitos. Según Halliday (2003), el niño posee diversos modelos sobre lo que el lenguaje le permite hacer: el instrumental (obtener cosas), el regulativo (controlar la conducta de otros), el interaccional (definir y consolidad grupos), el personal (tener conciencia de sí mismo), el heurístico (explorar el ambiente), el imaginativo (crear un ambiente ficticio), el representacional (comunicar proposiciones sobre procesos, personas, objetos, abstracciones, estados y relaciones del mundo real). No obstante, los profesores parecieran contar solo con uno de los modelos utilizados por el niño, el representacional, puesto que estarían enfocados en los contenidos curriculares. Además, agregarían otro modelo que no existiría en el mundo del niño: el modelo ritual, mediante el cual los profesores significarían el lenguaje como un conjunto de "buenos modales" de expresión. Dicho modelo no tendría contrapartida en los modelos funcionales que los niños han construido respecto del uso lingüístico.

2. La escuela posee ciertas expectativas del uso lingüístico con la cual no todos los estudiantes están familiarizados, especialmente aquellos que provienen de sectores deprivados, lo cual es especialmente relevante en el caso del lenguaje escrito. No todos los niños tienen la experiencia de haber sido ayudados por sus cuidadores para elaborar la información que expresan, precisar ideas, tomar distancia de la situación concreta, flexibilizar el punto de vista para narrar un hecho, estimular la lectura compartida, interactuar produciendo distintos tipos de mensajes, solicitar y dar explicaciones. Como sostiene Scheppegrell (2004), muchas tareas escolares son versiones formalizadas de funciones que algunos niños, fundamentalmente de clase media, realizan en las conversaciones cotidianas en sus hogares, mientras que para otros constituyen un conjunto de expectativas implícitas que no son capaces de develar, lo cual se agrava por la incapacidad de algunos profesores de detectar las ayudas necesarias para que estos niños aprendan a utilizar los recursos discursivos pertinentes a tales demandas. Según Halliday (2003), los niños que 
manejan un código lingüístico restringido no conocerían como utilizar el lenguaje para aprender y para participar como un individuo en la situación de aprendizaje.

3. El aprender a escribir es transitar desde un uso interactivo del lenguaje a uno cerrado en el cual la interacción social no es evidente. Según Bereiter y Scardamalia (1982), existen dos cambios relevantes cuando un niño aprende a escribir: pasar de la expresión oral a la gráfica y de la comunicación cara a cara a una comunicación con una audiencia remota. Paralelamente, al escribir, los niños enfrentan problemas de recuperación y estructuración del contenido, cuya resolución no necesariamente implica que consideren los propósitos por los cuales escriben, de tal modo que la activación de su conocimiento previo y el despliegue que hacen de él en el texto sea realmente estratégico.

A partir de tales reflexiones, se plantea que una didáctica de la lengua en la escuela debiera tener al lenguaje como contenido y medio de enseñanza. Si se aplica este principio a la escritura, se puede sostener que se requiere partir por identificar los géneros que se utilizan en la escuela, caracterizarlos léxico-gramaticalmente y describirlos estructuralmente, con el propósito de contar con antecedentes que posibiliten enfocar la atención de los profesores y alumnos en los patrones lingüísticos mediante los cuales tales géneros se realizan (Schleppegrell, 2004).

\subsection{La producción de narraciones en la escuela}

En un sentido amplio, la narración puede definirse como una secuencia temporal de eventos. En una perspectiva más restringida, se concibe como un encadenamiento temporal de acciones articuladas en torno a un nudo, es decir, una complicación que tensiona el relato y que transforma una situación inicial en una situación de desequilibrio, cuya resolución genera una nueva situación final de equilibrio (Adam, 1992; Adam \& Lorda, 1999; Klein, 2007). Para algunos autores, el nudo es el aspecto central que diferencia una narración de una descripción de acciones (Adam, 1992) o una narración de un recuento de acciones (Rose \& Martin, 2012). Sería esta parte de la estructura la que dotaría a la narración de interés (Klein, 2007).

Dado que la narración es una modalidad textual relevante en la socialización familiar y escolar, los niños desarrollan un conjunto de 
expectativas sobre la narración, las cuales guían sus actividades de recepción como las de producción. En el plano de la escritura, el análisis de las narraciones ha permitido constatar un progresivo avance en el uso de conectores causales, temporales y adversativos y la disminución de la " $y$ " polifuncional, aunque existirían diferencias entre diversos estratos socioeconómicos (Álvarez, 1996). A su vez, las prácticas de lectura y el uso de la lengua escrita incrementarían la capacidad de referir el discurso de los otros mediante el estilo indirecto, operación retórica que implica una serie de transformaciones en los tiempos verbales, las categorías gramaticales de persona y las locuciones adverbiales de tiempo y lugar (Bosco Figuereido, 1998).

Si bien a lo largo de la escolaridad persisten problemas de puntuación y ortografía, el dominio creciente de recursos gramaticales posibilita dotar los textos de coherencia. En efecto, a partir de los 10 años, los niños prácticamente no escribirían narraciones incoherentes (Matute \& Leal, 1996; Cabrera, 2003). La persistencia de los problemas de puntuación y ortografía posiblemente se deba a una menor atención a los aspectos superficiales del texto en función de concentrarse en el desarrollo de la acción, lo cual supone prestar atención a la estructura textual, la coherencia global, el tema, la precisión léxica, entre otros factores (Sánchez Abchi, Borzone \& Diuk, 2007).

En una evaluación holística de las narraciones escritas producidas por estudiantes de $3^{\circ}$ básico, Benítez (2009) pudo constatar que los estudiantes no consideran la audiencia y prácticamente no utilizan el lenguaje figurativo, manifestando, además, dificultades para la descripción de personas o lugares para profundizar la calidad del relato. Congruentemente, más que el contenido global del relato, el uso de recursos lingüísticos y textuales marcarían las diferencias entre narración oral y narración escrita (Aravena, 2011).

\section{Metodología}

Se construyó un corpus de textos escritos de estudiantes de $3^{\circ}, 5^{\circ}$ y $7^{\circ}$ básicos funcionales a la descripción de los cambios léxico-gramaticales que se registran a medida que se avanza en la escolaridad. Para hacerlo, se elaboraron dos tareas de escritura: una narración espontánea y una narración guiada por imágenes. Estas tareas se sometieron al juicio experto de tres profesoras básicas que tenían las siguientes características: 
a) Profesora de aula de 50 años, con mención en Lenguaje y Comunicación, egresada de un Magíster en Didáctica e Innovación Pedagógica.

b) Académica de 33 años que se desempeña en el ámbito de la formación inicial docente y asesora de establecimientos escolares en el ámbito de la gestión curricular.

c) Académica de 49 años que imparte cursos de Didáctica de la Lengua y tesista de un Magíster en Alfabetización y Escritura.

Luego de este proceso de validación, se procedió a aplicar la tarea de escritura en dos tipos de colegios: un particular subvencionado de nivel socioeconómico medio alto -según el Mineduc- y un establecimiento municipal de nivel socioeconómico medio bajo. En cada uno de ellos se trabajó con dos cursos de $3^{\circ}, 5^{\circ}$ y $7^{\circ}$ básicos.

La aplicación se efectuó durante el primer semestre de 2014 como una actividad de la asignatura de Lenguaje y Comunicación dirigida por la profesora o profesor titular de cada curso, a quien se le había explicado previamente el guion de cada tarea de escritura. El plazo máximo para la realización de cada tarea fue de 80 minutos. Los estudiantes que terminaban podían ilustrar sus escritos y, luego, desarrollar una lectura del libro de texto del nivel. Cabe indicar que el investigador estuvo presente en la sala de clase con la venia de la dirección del establecimiento y la del profesor o profesora titular. En total, la actividad se desarrolló con 12 cursos. En el establecimiento particular subvencionado se recogieron los textos de 133 niños y, en el municipal, los de 142 estudiantes. Dichos textos fueron transcritos para facilitar el análisis.

En los resultados se describe la tarea, el resultado del proceso de validación y un análisis exploratorio inicial de los textos.

\section{Resultados}

\subsection{La narración espontánea}

Esta tarea buscaba que los estudiantes eligieran una vivencia personal para contarla a otros. Para hacerlo, se dieron indicaciones generales sobre el tema, la audiencia y el propósito, de tal modo de dejar abierto la estructuración del contenido, la extensión y el efecto buscado. La tarea 
partió por activar el conocimiento previo del curso sobre la actividad desarrollada por los escritores y, luego, el docente describió de modo muy general la labor de los escritores, enfatizando el acto de reflexionar sobre lo vivido. Para concretar dicha descripción, se ejemplificó lo dicho con una narración simple, con un tema cercano a la cotidianeidad del estudiantado y con un escolar como protagonista. Se puso especial énfasis en que esta narración girara en torno a un nudo y fuera lineal, para evitar grandes complejidades estructurales que pudiera hacerla de difícil alcance para los escolares de diferentes edades. Posteriormente, se les planteó la tarea como un "jugar a ser escritores" y se apeló al recuerdo de una vivencia personal, generando las condiciones para que reflexionaran sobre ellas, las acciones desplegadas y los sentimientos involucrados. Finalmente, se les planteó que desarrollaran un borrador pensando que el relato sería leído por muchas personas. Se estimó un tiempo de trabajo y se explicó la consigna de que debían corregir la primera versión del escrito. En general, este último aspecto implicó que los estudiantes de todos los niveles reescribieran sus relatos en otra hoja, pero sin grandes cambios, salvo algunos de carácter caligráfico y algunos dibujos. Solo algunos consultaron al profesor o profesora por la ortografía de una palabra. En consecuencia, se puede afirmar que los estudiantes de todos los niveles parecieran no haber internalizado criterios de evaluación para reescribir sus relatos. A continuación, se reproduce el guión utilizado.

\section{TAREA 1: NARRACIÓN ESPONTÁNEA}

\section{Objetivo}

Generar las condiciones para que los estudiantes representen por escrito algún evento de su vida cotidiana que consideren importante en su vida y que deseen relatar a otros.

Instrucciones

1. Preguntarle a los niños qué es lo que hacen los escritores (motivar una conversación al respecto).

2. Se contextualiza la actividad y se les da instrucciones, detallándose a continuación. 
a) "Saben ustedes que muchos escritores, cuando escriben sus obras (ya sean cuentos, fábulas, novelas), piensan en algo que les ha pasado; algo que puede ser divertido, triste, interesante. Estos escritores recuerdan qué pasó, cómo se sintieron, qué hicieron, cómo se sintieron otras personas y qué sintieron esas otras personas. O sea, esos escritores tratan de darle vida en la mente a lo que ellos vivieron."

b) “Veamos un ejemplo. 'Iba un día caminando hacia la escuela. Estaba cruzando una plaza y me sentía contento. Quería pasarlo bien con mis compañeros. Teníamos un paseo y eso me gusta mucho. De repente, sentí un ladrido muy despacio. Miré para todos lados y en un rincón de la plaza había un pequeño perrito. Estaba solo. Pensé en llevármelo. No sé qué iban a decir en el colegio, pero me gustó mucho, lo vi tan tierno y solito. Estaba a punto de tomarlo en brazos, cuando apareció una señora. El perrito era de ella. Me sentí contento, porque no estaba solito y parece que la señora lo quería mucho."

c) "Bueno, esta historia podría continuar, pero la idea era que supiéramos cómo podríamos hacerlo."

d) "Nosotros ahora vamos a jugar a ser escritores. Vamos a tratar de recordar algo que nos haya pasado y que queramos contarle a otros. Cada uno elige qué es lo que quiere contar. A ver, recordemos algo que nos haya pasado y que queramos contar. ¿Qué podría ser? Recordemos."

e) “Ahora vamos a recordar bien esa experiencia. ¿Qué pasó? ¿Qué hicimos? ¿Cómo nos sentimos? ¿Con quiénes estaba yo? ¿Qué hicieron las otras personas que estaban conmigo? Tratemos de recordar bien esa experiencia. Pensemos."

f) "Ahora vamos a escribir lo que recordamos para que otras personas puedan leerlo. Recuerden que somos escritores y queremos que muchas personas lean lo que escribimos. Entonces tenemos que hacerlo en forma bien clara." 
g) "Cada uno en silencio va a escribir su historia. Concentrémonos. Tenemos unos 30 minutos más o menos para escribir."

h) "Los alumnos que hayan terminado, van a leer lo que escribieron y lo van a corregir (ortografía, caligrafía, claridad). Lo van a pasar en limpio para que sea claro y fácil de leer."

Para validar esta tarea, se utilizó una pauta compuesta de tres criterios: grado de comprensión de las instrucciones, motivación para que los estudiantes escribieran y la libertad para elegir la experiencia a ser narrada. Además, se proporcionó un espacio para que las expertas pudieran realizar sugerencias orientadas a mejorar las instrucciones. El resultado se muestra a continuación.

\begin{tabular}{|c|c|c|c|}
\hline Aseveraciones & Evaluadora 1 & Evaluadora 2 & Evaluadora 3 \\
\hline $\begin{array}{l}\text { Las instrucciones son comprensibles } \\
\text { para niños y niñas del segundo ciclo } \\
\text { básico. }\end{array}$ & $\begin{array}{l}\text { Muy de } \\
\text { acuerdo }\end{array}$ & De acuerdo & $\begin{array}{l}\text { Muy de } \\
\text { acuerdo }\end{array}$ \\
\hline $\begin{array}{l}\text { La tarea propuesta motiva la } \\
\text { producción de una narración por } \\
\text { parte de alumnos y alumnas de } \\
\text { segundo ciclo básico. }\end{array}$ & $\begin{array}{l}\text { Muy de } \\
\text { acuerdo }\end{array}$ & $\begin{array}{l}\text { Muy de } \\
\text { acuerdo }\end{array}$ & $\begin{array}{l}\text { Muy de } \\
\text { acuerdo }\end{array}$ \\
\hline $\begin{array}{l}\text { Las instrucciones permiten que } \\
\text { el alumno o la alumna tenga la } \\
\text { libertad para elegir la experiencia } \\
\text { que desea narrar. }\end{array}$ & $\begin{array}{l}\text { Muy de } \\
\text { acuerdo }\end{array}$ & $\begin{array}{l}\text { Muy de } \\
\text { acuerdo }\end{array}$ & $\begin{array}{l}\text { Muy de } \\
\text { acuerdo }\end{array}$ \\
\hline
\end{tabular}

El grado de acuerdo en que la actividad es apropiada para estudiantes de segundo ciclo básico es alto (97\%). Esto se reafirma por las sugerencias realizadas. La primera evaluadora destacó que las instrucciones permitían la creación libre y su grado de propiedad para alumnos de diversas edades y etapas de desarrollos. La segunda hizo una serie de consideraciones que sirvieron para precisar la redacción del ejemplo y evitar algunas reiteraciones. La tercera manifestó simplemente que las instrucciones eran apropiadas para escolares de $3^{\circ}, 5^{\circ}$ y $7^{\circ}$ básico.

A continuación se presenta una breve exploración de los textos producidos, teniendo en cuenta el tipo de texto, la presencia de título y el tipo de final. 
Cuadro 1.

Tipo de texto producidos por los escolares de acuerdo con el tipo de colegio y curso, expresado en porcentaje.

\begin{tabular}{lllll}
\hline Tipo de texto & $\begin{array}{l}\text { Colegio } \\
\text { Municipal }\end{array}$ & & $\begin{array}{l}\text { Colegio } \\
\text { Particular } \\
\text { Subencionado }\end{array}$ & \\
\hline & $\begin{array}{l}\text { Descripción de } \\
\text { acciones }\end{array}$ & Narraciones & $\begin{array}{l}\text { Descripción de } \\
\text { acciones }\end{array}$ & Narraciones \\
\hline Tercero básico & $40 \%$ & $60 \%$ & $73.3 \%$ & $26.7 \%$ \\
\hline Quinto básico & $52.5 \%$ & $47.5 \%$ & $48.7 \%$ & $51.3 \%$ \\
\hline Séptimo básico & $60 \%$ & $40 \%$ & $38.1 \%$ & $61.9 \%$ \\
\hline TOTAL & $51.4 \%$ & $48.6 \%$ & $54 \%$ & $46 \%$ \\
\hline
\end{tabular}

En ambos establecimientos, los escolares tienden a producir más descripciones de acciones que narraciones centradas en una complicación que provoca un desequilibrio en una situación inicial relativamente estable. La diferencia es estadísticamente significativa (Chi cuadrado $17,57, \mathrm{p}<.001)$ y el origen de esta significación se encuentra en la gran cantidad de alumnos de tercero básico que en los colegios particulares subvencionados emplea la descripción de acciones para relatar por escrito sus vivencias personales. En cuanto a los demás cursos y tipos de colegios, no se observan ni asociaciones ni diferencias estadísticamente significativas.

A nivel descriptivo, es posible observar que los textos escritos por los alumnos del establecimiento municipal muestran un patrón diferente al de los alumnos del colegio particular subvencionado. En efecto, los niños de tercero básico municipal escriben más narraciones en comparación con sus compañeros de $5^{\circ}$ y $7^{\circ}$ básico, lo cual podría explicarse por estrategias particulares que utilizaría la profesora. En lo relativo a la narración, resulta llamativo el hecho de que la progresión es muy moderada y tiende a la baja. Esto pudiera significar que hay menos concentración en los elementos estructurales de este tipo de texto o menos prácticas de escritura a medida de que se avanza en la escolaridad.

En el colegio particular subvencionado se puede constatar que la cantidad de alumnos que utiliza la descripción de acciones para relatar una experiencia personal disminuye a medida que avanza el nivel. 
En consecuencia, es posible concluir que la descripción de acciones es básicamente empleada por los estudiantes de tercero básico (lo que genera la única diferencia estadísticamente significativa), pero es cada vez menos usada a medida que se aumenta el nivel. En cambio, al observar la narración caracterizada por la presencia de una complicación, la cantidad de estudiantes que la emplea va aumentando progresivamente. Esto parece sugerir un cambio evolutivo, lo que implica un mejor manejo de la capacidad de expresar por escrito las características propias de la narración a medida que los estudiantes avanzan en los niveles de escolaridad.

Al considerar el factor sexo, solo se observan diferencias estadísticamente significativas en el colegio particular subvencionado, no así en el municipal. En concreto, los hombres utilizan menos la descripción de acciones para relatar su experiencia que las mujeres. Particularmente, si se observa el $7^{\circ}$ básico, el $58.7 \%$ de las mujeres escribieron narraciones y el $68.8 \%$ de los varones.

Cuadro 2.

Presencia de título según tipo de texto por estudiantes de dos tipos de colegios expresado en porcentaje.

\begin{tabular}{lllll}
\hline $\begin{array}{l}\text { Presencia de } \\
\text { título según } \\
\text { tipo de texto }\end{array}$ & $\begin{array}{l}\text { Colegio } \\
\text { Municipal }\end{array}$ & $\begin{array}{l}\text { Descripción de } \\
\text { acciones }\end{array}$ & Narraciones & $\begin{array}{l}\text { Colegio } \\
\text { Particular } \\
\text { Subvencionado }\end{array}$ \\
\hline Descripción de & $\begin{array}{l}\text { Narraciones } \\
\text { acciones }\end{array}$ & \\
\hline Tercero básico & $77.3 \%$ & $78.8 \%$ & $69.7 \%$ & $83.3 \%$ \\
\hline Quinto básico & $81.2 \%$ & $82.8 \%$ & $89.5 \%$ & $95 \%$ \\
\hline Séptimo básico & $84.6 \%$ & $88.5 \%$ & $87.5 \%$ & $73.1 \%$ \\
\hline TOTAL & $81.7 \%$ & $82.9 \%$ & $79.4 \%$ & $82.8 \%$ \\
\hline
\end{tabular}

En general, todos los estudiantes tienden a titular sus escritos, independientemente del tipo de textos del cual se trate. No se observan diferencias estadísticamente significativas en ambos establecimientos.

En relación con la coherencia, los títulos incoherentes, en el sentido de que no se relacionan con el tema central del escrito ni aluden a algún elemento presente en él para dar pistas sobre el contenido, son muy bajos 
(representan uno o dos sujetos de cada curso). En cambio, los títulos totalmente coherentes (aquellos que sintetizan el tema central del escrito en la perspectiva de orientan la construcción del sentido global por parte un lector eventual) son relativamente altos. En el colegio municipal corresponde al $44.6 \%$ de las descripciones de acciones y al $57.4 \%$ de las narraciones; en el particular subvencionado al $52.9 \%$ de las descripciones de acciones y al $48.9 \%$ de las narraciones. No se observan diferencias significativas.

\section{Cuadro 3.}

Tipo de final en textos narrativos según curso y tipo de establecimiento, expresado en porcentaje.

\begin{tabular}{lll}
\hline $\begin{array}{l}\text { Tipo de final en } \\
\text { narraciones }\end{array}$ & Colegio Municipal & $\begin{array}{l}\text { Colegio Particular } \\
\text { Subvencionado }\end{array}$ \\
\hline Nercero básico & $66.7 \%$ & No abrupto \\
\hline Quinto básico & $93.1 \%$ & $58.3 \%$ \\
\hline Séptimo básico & $92 \%$ & $75 \%$ \\
\hline TOTAL & $83 \%$ & $69.2 \%$ \\
\hline
\end{tabular}

Se consideró como un final no abrupto aquellos relatos cuya situación final implica un nuevo equilibrio y no se dejan posibles dudas en torno a la resolución de la complicación. En los textos narrativos analizados, se observa que los estudiantes del colegio municipal tienen mejor desempeño que los del colegio particular subvencionado. En ambos establecimientos, hay una mejora significativa entre $3^{\circ}$ y $5^{\circ}$ básico.

\subsection{La narración guiada por imágenes}

Esta tarea se orientó a la presentación de un estímulo consistente en una serie de imágenes tomadas del cuento álbum El Túnel de Anthony Brown. Estas fueron presentadas en un ppt con una instrucción general orientada a que los estudiantes pudieran relacionarlas para inventar un relato. Se eligieron las imágenes de este cuento considerando los siguientes criterios: los protagonistas son una niña y un niño, su edad 
corresponde a la de escolares de enseñanza básica, las imágenes eran suficientemente explícitas para poder construir potencialmente diferentes relatos y utilizar diferentes recursos retóricos (diálogos, tipo de narrador, descripciones, metáforas, personificaciones, etc.). El hecho de que los protagonistas fueran un niño y una niña se realizó con el propósito de favorecer la identificación de los estudiantes. En las imágenes claramente se describen algunas complicaciones que tensionan el relato hasta llegar un climax y que finalmente se resuelven generando una nueva situación de equilibrio.

La instrucción previa a la exhibición del ppt buscaba a que los estudiantes fueran imaginando en silencio lo que ocurría en la serie de imágenes para que formularan un relato orientado a la lectura de otros, aspecto que se reiteró a lo largo de la exhibición. El rol que debían asumir era el de escritores y la audiencia se fue especificando desde un planteamiento muy general a profesores y alumnos de una universidad que querían saber cómo ellos escribían. De este modo, se proporcionaron los elementos centrales de la situación retórica. Además, se enfatizó que primero escribirían un borrador que deberían revisar y reescribir. $\mathrm{Al}$ igual que en la primera tarea, los niños simplemente se dedicaron a transcribir lo escrito en el borrador y, algunos, a realizar consultas sobre la ortografía de algunas palabras. En general, los aspectos revisados fueron la caligrafía y la presentación a la cual se le adosaron algunos dibujos. A continuación, se reproduce el guion utilizado.

TAREA 2: NARRACIÓN DIRIGIDA POR UNA SECUENCIA DE IMÁGENES

Objetivo

Motivar la producción de una narración escrita en la cual los estudiantes puedan manifestar recursos lingüísticos y discursivos que poseen.

Para la pauta de validación que se sometió al juicio de las tres profesoras expertas, se consideraron los dos primeros criterios de la pauta anterior y se agregó uno específico relacionado con la pertinencia de las 
Instrucciones:

1. Las instrucciones que se les deben entregar a los alumnos deben ser explicadas de la siguiente forma:

a) "Les voy a presentar una serie de dibujos. Ustedes tienen que ir imaginando qué es lo que va pasando con los personajes que aparecen en estos dibujos. Imagínense que ustedes son escritores y que desean contar lo que les pasó a los niños que aparecen en los dibujos. Lo que escriban será leído por otras personas de muchos lugares. Por lo tanto, tienen que escribir con claridad lo que van a relatar."

b) "Mientras observamos los dibujos tienen que estar en completo silencio, imaginando lo que ocurre."

c) "Observen cada imagen con atención y vayan imaginando la historia" (se presenta el ppt con imágenes del cuento El túnel de Anthony Browne, dando unos 15 segundos por imagen para que los niños puedan observarla detenidamente).

d) "Recuerden las imágenes y vayan pensando cómo va a ser la historia que van a contar. Voy a volver a mostrar las imágenes por si quieren recordar mejor algunos detalles" (se vuelve a mostrar el diaporama).

e) "Ahora, en silencio, cada uno se va a concentrar en escribir su historia. Primero vamos a hacer un borrador. Lo importante es que se imaginen que muchas personas de diferentes lugares van a leer lo que ustedes escriban y que ustedes no van a estar para aclararles nada."

f) "Las primeras personas que van a leer lo que ustedes escriban son profesores y alumnos de una universidad que están haciendo una investigación sobre cómo escriben los niños y niñas de $3^{\circ}$ básico $\left(5^{\circ}\right.$ o $7^{\circ}$ según corresponda). Ellos quieren saber cómo ustedes escriben para después contarle a diferentes profesores cómo escriben los niños y niñas de $3^{\circ}$ básico. Entonces, lo que ustedes escriban es muy importante." 
g) "Las personas que hayan terminado, van a leer en silencio su historia, la van a corregir (ortografía, caligrafía, claridad) para que sea fácil de leer y comprender. Recuerden que la van a leer muchas otras personas y que ustedes no van a estar para aclararles nada."

h) "Para terminar, van a pasar su historia en limpio, con letra clara y fácil de leer."

imágenes para estimular la creatividad de los estudiantes. El resultado se muestra a continuación:

\begin{tabular}{llll}
\hline Aseveraciones & Evaluadora 1 & Evaluadora 2 & Evaluadora 3 \\
\hline $\begin{array}{l}\text { Las instrucciones son } \\
\text { comprensibles para niños y } \\
\text { niñas del segundo ciclo básico. }\end{array}$ & $\begin{array}{l}\text { Muy de } \\
\text { acuerdo }\end{array}$ & De acuerdo & $\begin{array}{l}\text { Muy de } \\
\text { acuerdo }\end{array}$ \\
\hline $\begin{array}{l}\text { La tarea propuesta motiva la } \\
\text { producción de una narración } \\
\text { por parte de alumnos y } \\
\text { alumnas de segundo ciclo } \\
\text { básico. }\end{array}$ & Muy de & Muy de & Muy de \\
acuerdo & acuerdo & \\
\hline $\begin{array}{l}\text { Las imágenes elegidas son } \\
\text { pertinentes para el despliegue } \\
\text { de la creatividad de los } \\
\text { estudiantes del segundo ciclo } \\
\text { básico en la construcción de } \\
\text { una narración escrita }\end{array}$ & De acuerdo & De acuerdo & Muy de \\
\hline
\end{tabular}

El grado de acuerdo sobre la pertinencia de la tarea es bastante alto (91.7\%). En efecto, en las sugerencias se tiende a valorar las imágenes como un estímulo adecuado para la creación de diferentes historias, especialmente debido a que permiten realizar diferentes tipos de inferencia. Dos de las evaluadoras coinciden en indicar que dichas imágenes podrían ser poco llamativas para los estudiantes de $7^{\circ}$ año, debido que sus intereses son diferentes y a que tienen acceso a productos audiovisuales más elaborados.

A continuación, se presenta una breve exploración de los textos producidos, teniendo en cuenta el tipo de texto, la presencia de título y el tipo de final. 
Cuadro 4.

Tipo de texto producidos por los escolares de acuerdo con el tipo de colegio y curso, expresado en porcentaje.

\begin{tabular}{lllll}
\hline Tipo de texto & $\begin{array}{l}\text { Colegio } \\
\text { Municipal }\end{array}$ & & \multicolumn{3}{l}{$\begin{array}{l}\text { Colegio } \\
\text { Particular } \\
\text { Subvencionado }\end{array}$} & \\
\hline & $\begin{array}{l}\text { Descripción } \\
\text { de acciones }\end{array}$ & Narraciones & $\begin{array}{l}\text { Descripción de } \\
\text { acciones }\end{array}$ & Narraciones \\
\hline Tercero básico & 76.7 & 23.3 & 86.7 & 13.3 \\
\hline Quinto básico & 70 & 30 & 86.7 & 13.3 \\
\hline Séptimo básico & 63.3 & 36.7 & 80 & 20 \\
\hline TOTAL & 70 & 30 & 84.4 & 14.6 \\
\hline
\end{tabular}

Significativamente, en la segunda condición de escritura, los estudiantes tienden a describir las acciones observadas. En concreto, el $48.2 \%$ de los escritos de los estudiantes del colegio municipal y el $71.4 \%$ de los del particular subvencionados son resúmenes que siguen el orden de las imágenes observadas. La reelaboración creativa es prácticamente nula. En términos generales, tiende a primar el recuerdo de lo visto, más que la construcción de una narración centrada en una complicación.

Al comparar los escritos de los estudiantes de ambos establecimientos, no se observa una diferencia estadísticamente significativa (chi cuadrado 1.94, $\mathrm{p}=0.39$ ). En otras palabras, no se encontraron diferencias considerando las variables de modalidad del establecimiento y de nivel de escolaridad. A nivel descriptivo, al revisar la frecuencia de descripción de acciones no se observa una tendencia hacia la disminución ni hacia el aumento. Al observar las frecuencias de narraciones escritas, existe una tendencia leve a medida que se avanza en la escolaridad, pero esta no es estadísticamente significativa. Por tanto, se puede concluir que los alumnos de los dos establecimientos muestran el mismo patrón y no dan muestras de cambios evolutivos a medias que se avanza en la escolaridad.

Cuadro 5.

Presencia de título según tipo de texto por estudiantes de dos tipos de colegios expresado en porcentaje. 


\begin{tabular}{lllll}
\hline $\begin{array}{l}\text { Presencia de título } \\
\text { según tipo de texto }\end{array}$ & $\begin{array}{l}\text { Colegio } \\
\text { Municipal }\end{array}$ & \multicolumn{3}{l}{$\begin{array}{l}\text { Colegio } \\
\text { Particular } \\
\text { Subvencionado }\end{array}$} \\
\hline & $\begin{array}{l}\text { Descripción } \\
\text { de acciones }\end{array}$ & Narraciones & $\begin{array}{l}\text { Descripción de } \\
\text { acciones }\end{array}$ & Narraciones \\
\hline Tercero básico & 100 & 100 & 88.5 & 75 \\
\hline Quinto básico & 100 & 100 & 100 & 100 \\
\hline Séptimo básico & 100 & 90.9 & 62.5 & 83.3 \\
\hline TOTAL & 100 & 96.3 & 84.2 & 85.7 \\
\hline
\end{tabular}

En general, la tendencia es que los estudiantes titulen sus escritos y que reproduzcan el mismo título del cuento cuyas imágenes fueron observadas. Solo en un $46.2 \%$ de las narraciones y en un $33.3 \%$ de las descripción de acciones se reelabora el título original del cuento. En general, dichas relaboraciones implican agregar una expresión adjetiva, por ejemplo, "el túnel misterioso", "el túnel mágico", “el túnel oscuro", "el túnel tenebroso", "el túnel malvado", "el túnel maravilloso", "el túnel de los secretos", "el túnel del temor". En menor medida, se hace alusión a los protagonistas, por ejemplo, "el niño y la niña en el túnel", "los hermanos a través del túnel", "dos hermanos en un mundo encantado". Son pocas las reelaboraciones completas del título, como "el mundo mágico", "el bosque embrujado", "un lugar secreto".

Cuadro 6.

Tipo de final en textos narrativos según curso y tipo de establecimiento, expresado en porcentaje.

\begin{tabular}{lll}
\hline $\begin{array}{l}\text { Tipo de final en } \\
\text { narraciones }\end{array}$ & Colegio Municipal & $\begin{array}{l}\text { Colegio Particular } \\
\text { Subvencionado }\end{array}$ \\
\hline No abrupto & No abrupto \\
\hline Tercero básico & 57.1 & 0 \\
\hline Quinto básico & 55.6 & 50 \\
\hline Séptimo básico & 54.6 & 66.7 \\
\hline TOTAL & 51.9 & 42.9 \\
\hline
\end{tabular}

De los escritos que corresponden a narraciones ( $30 \%$ en el colegio municipal y $14.6 \%$ en el particular subvencionado), existe un importante porcentaje de estudiantes que termina abruptamente el relato, es decir, no logran darle un cierre coherente en términos de establecer un desenlace 
para la complicación que signifique un nuevo equilibrio en la situación final. Los patrones entre los textos producidos por los estudiantes de los dos establecimientos son bastante disímiles. En el municipal, se tiende a mantener estable el porcentaje de estudiantes que logran darle un final no abrupto a sus narraciones; mientras que en el particular subvencionado, se aprecia un patrón de mejora progresiva donde el cambio más significativo es desde $3^{\circ}$ a $5^{\circ}$ año.

Al considerar solamente las narraciones, entendidas como la presencia de una complicación, producidas por los estudiantes de diferentes niveles, se aprecia que el final es menos abrupto en la condición de escritura espontánea y menor en la condición de escritura guiada por imágenes. Esto se explicaría por la demanda que significa recordar las imágenes y la secuencia en que aparecen que, al parecer, es el foco de atención de los estudiantes cuando escriben.

\section{Conclusiones}

Las dos tareas de escrituras son pertinentes según la opinión de los jueces expertos y el corpus obtenido para que los niños de diversos niveles de educación básica produzcan textos escritos relativamente coherentes. A partir de su aplicación, es posible configurar un corpus para abordar la producción escrita como producto y aproximarse a los escritos producidos para analizar diversos fenómenos de carácter lingüístico y discursivo.

En relación con la modalidad textual producida, si se define la narración desde una perspectiva amplia como secuencia de acciones en el tiempo, todos los estudiantes lograron producir este tipo de escritos. $\mathrm{Si}$ se define la narración desde una perspectiva restringida, como un tipo de texto que gira en torno al surgimiento y resolución de una complicación, se constata que la narración espontánea es la condición de escritura que permite mayores niveles de logro por parte de los estudiantes ( $48 \%$ en el colegio municipal y $46 \%$ en el particular subvencionado) en contraposición con la condición de escritura de narración guiada por imágenes donde estos niveles se reducen significativamente (30\% en el colegio municipal y $14.6 \%$ en el particular subvencionado). Pareciera ser que en la segunda condición de escritura tiende a primar el interés de los estudiantes por recordar los eventos presentes en las imágenes y las 
secuencias que estas aparecen más que en una elaboración creativa de un texto narrativo.

En su mayor parte, los estudiantes tienden a asignar títulos relativamente coherentes a sus producciones escritas, aunque en la segunda condición de escritura la tendencia es a reproducir el mismo título original del cuento, el cual aparece en la primera imagen mostrada. Las reelaboraciones de dicho título se orientan básicamente a la adición de un adjetivo.

En general, se puede constatar que no existen diferencias significativas. Por el tipo de texto producido en ambas condiciones de escrituras, considerando la variable tipo de establecimiento. En esta línea, en la primera condición de escritura serían los estudiantes de $3^{\circ}$ básico del establecimiento particular subvencionados los que tiende a escribir una mayor proporción de descripciones de acciones.

Los patrones evolutivos diferentes que se observa en torno a escribir narraciones con la presencia de una complicación que se constató en la primera condición de escritura entre los dos tipos de establecimientos, posiblemente se explique por el tiempo dedicado a las prácticas de escrituras. En esta línea, una mayor frecuencia de actividades de escritura, especialmente si se enfocan en los elementos estructurales y en la calidad de los recursos lingüísticos empleados, redundará en narraciones escritas de mejor calidad. 


\section{Referencias bibliográficas}

Adam, J. M. (1992). Les textes: types et prototypes. Paris: Natham.

Adam, J. M. \& Lorda, C. (1999). Lingüística de los textos narrativos. Barcelona: Ariel.

Álvarez, G. (1996). Conexión textual y escritura en narraciones escolares. Onomázein, 1, 11-29.

Aravena, S. (2011). El desarrollo narrativo a través de la adolescencia: estructura global de contenido y referencia personal. Signos, 44 (77), 2155-232.

Beard, R.; Myhill, D.; Riley, J. \& Nystrand, M. (2009). The Sage handbook of writing development. London: Sage.

Benitez, R. (2009). Análisis descriptivo de narraciones escritas por niños y niñas de tercer año básico. Literatura y Lingüística, 20, 103-123.

Bereiter, C. \& Scardamalia, M. (1982). De la conversación a la redacción: el papel de la instrucción en un proceso evolutivo [En línea]. Disponible en: www.geocities.com/ prolenguaje/Bersca82.htm.

Bosco Figuereido, J. (1998). A reproducão da enunciacão indireita en narrativas infantis. Revista de letras 1/2, (20), 91-102.

Cabrera, (2003). Producción de textos narrativos escritos: estudio descriptivo-comparativo en alumnos de $2^{\circ}, 3^{\circ}$ y $4^{\circ}$ básico. Psykhé, 12 (2), 121-132.

Cassany, D. (1999). Construir la escritura. Barcelona: Paidós.

Christie, F. \& Derewianka, B. (2010). School Discourse. London: Continuum.

De Beaugrande, R. (1997). New foundations for a science of text and discourse. Cognition, communication, and the access to knowledge and society. Vol LXI. New York: Academic Press.

Delicia, D. (2011). Madurez sintáctica y modo de organización del discurso: un estudio sobre la competencia gramatical adolescente en producciones narrativas y argumentativas. Onomázein, 24, 173-198. 
Flower, L. (1994). The construction of negotiated meaning. A social cognitive theory of writing. Carbondale: Southern Illinois University Press.

Flower, L. \& Hayes, J. (1981). A cognitive process theory of writing. College Composition and Communication, 32(4), 928-950.

Grabe, W. \& Kaplan, R (1996). Theory and practice of writing. New York: Longman.

Halliday, M. A. K. (2003). Relevant Models of Language. En Halliday, The language of Early Childhood (pp. 269-280). London: Continuum.

Hayes, J. (1996). A new framework for understanding cognition and effect in writing. En Levy \& Ransdell (Eds.), The science of writing. Theory, methods, individual differences and applications (pp. 1-27). Mahwa, N. J.: Lawrence Erbaum Associates Publishers.

Hyland, K. (2002). Teaching and researching writing. Essex: Pearson Education.

Kent, T. (1999). Post-process theory, beyond the writing-process paradigm. Illinois: Southern Illinois University.

Klein, I. (2007). La narración. Buenos Aires: Eudeba.

Koster, M.; Tribushinina, E.; de Jong, P. \& van den Bergh, H. (2015). Teaching children to write: a meta-analysis of writing intervention research. Journal of Writing Research, 7(2), 299-324.

Kostouli, T. (2009). A sociocultural framework: writing as social practice. En R. Beard, D. Myhill, J. Riley \& M. Nystrand (Eds.), The Sage handbook of writing development (pp. 98-116). London: Sage.

Matute, E. \& Leal, F. (1996). Se puede evaluar la coherencia en narraciones escritas por niños. Revista lectura y vida, 17(3), 5-16.

Meneses, A. (2006). Leer y escribir en la escuela : representaciones discursivas de los diferentes agentes educativos en 
las áreas prioritarias del curriculo escolar en NB3. Tesis para optar al grado de doctor en lingüística. Valparaíso: PUCV.

Meneses, A. (2008). Leer y escribir en una escuela chilena: representaciones discursivas de los diferentes agentes educativos en las áreas prioritarias del currículo escolar de NB3. Signos, 41(67), 257-278.

Nystrand, M. (2006). The social and historical context for writing research. En C. Mac Carthur, S Graham y J. Fitzgerald (Ed.), Handbook of writing research (pp. 11-27). New York: Guilford.

Pozo, J. I. (2001). Humana mente. El mundo, la conciencia y la carne. Madrid: Ediciones Morata.

Rose, D. (2009). Writing as linguistic mastery: the development of genrebased literacy pedagogy. En R. Beard, D. Myhill, J. Riley \& M. Nystrand (Ed.), The Sage handbook of writing development (pp. 151.166). London: Sage.

Rose, D. \& Martin, J. R. (2012). Learning to write, Reading to learn. Genre, knowledge and Pedagogy in the Sydney School. South Yorkshire: Equinox.

Schleppegrell, M. (2004). The Language of Schooling. A Functional Linguistics Perspective. Mahwah, N. J.: Lawrence Erlbaum Associates Publishers.

Sanchez Abchi, V., Borzone, A. M. \& Diuk, B. (2007). La escritura de textos en niños pequeños: relación entre transcripción y composición. Univ. Psychol, 6(3) 559-569.

Sotomayor, C.; Lucchini, G.; Bedwell, P.; Biedma, M.; Hernández, C. \& Molina, D. (2013). Producción escrita en la educación básica: análisis de narraciones de alumnos de escuelas municipales de Chile. Onomázein, 1(27), 5377. 